\title{
METRIC SURVEY AND BIM TECHNOLOGIES TO RECORD DECAY CONDITIONS
}

\author{
M. Lo Turco ${ }^{\text {a, }}$ M. Mattone ${ }^{\mathrm{a}}$, F. Rinaudo ${ }^{\mathrm{a}}$ \\ ${ }^{a}$ Dept. of Architecture and Design, Politecnico di Torino, Viale Mattioli 39, 10125 Turin, Italy \\ (massimiliano.loturco, manuela.mattone, fulvio.rinaudo)@polito.it
}

KEY WORDS: Metric survey, H-BIM, 3D decays, Data enrichment, Integrated workflow, TLS

\begin{abstract}
:
The paper proposes a method able to describe, classify and organize information assets concerned with Architectural Heritage, through the use of integrated survey procedures, mainly based on Terrestrial Laser Scanner (TLS). The point clouds are then imported into the Building Information Modeling (BIM) software to start with the modeling phase. With regard to this issue, in the last period Building Information Modeling is emerging as the most reliable method to manage architectural design and building processes. Literature supplies both theoretical approaches and several practical applications. However, very little researches are devoted to BIM applied to historical architecture, even if some initial results indicate the actual HBIM (Historic/Heritage BIM) as a possible instrument for the design of an intervention aimed at the conservation of the Cultural Heritage.

The focus of the research is the creation of parametric objects representing the preservation status of materials and building components: 3D modeling of decays in the BIM platform ensures to enrich the related database with graphic, geometric and alphanumeric data that can be effectively used to design and manage future interventions. The added value consists in its capability to associate new parameters that describe both the state of conservation of the materials and the detailed description of interventions needed to restore the building. The analyzed case study belongs to Ferrovie dello Stato (the main Italian Railways company) and it is part of the maintenance area, which was originally constituted by a roundhouse containing 51 sheltered railroad tracks and two big sheds.
\end{abstract}

\section{INTRODUCTION}

In the last years, the use of digital technologies has completely changed and improved the working methods related both to threedimensional metric survey and to the representation and modeling phases in the architectural heritage domain (Santagati, 2016a). Cultural heritage sites and our valuable historical architectural heritage require 3D models in order to achieve a significant benefit from their digitalization (Quattrini, 2015a). These models are increasingly available thanks to rapid technological progress in the field of acquisition, methods based on laser scanners and/or digital photogrammetry (Barazzetti, 2010, Chiabrando, 2013a). Nowadays 3D acquisition techniques (laser scanning, digital photogrammetry) support easy and quick point cloud acquisition. Even if the use of laser scanning is still expensive, a set of low cost solutions for digital photogrammetry is available on the market and allows for the acquisition of architectural elements or details (Lo Turco, 2010a).

The obtained point cloud registers non-interpreted geometrical, material and color data, as well as information related to the visible pathologies. Nevertheless, the point cloud is not a semantic model (Lo Buglio, 2012a), but it is constituted by a large number of points that are ontologically indistinct before the geometrical restitution. Up to now, there is not automatic processing tool available that allows the identification of complex shapes (such as the ones that characterize historical buildings) and turns them into geometric models.

Regarding to the new methodologies more and more used in the field of the construction process, we can state that Building Information Modeling (BIM) is emerging as one of the most reliable method to manage architectural design and building processes. One of the most meaningful definitions of Building Information Modeling in international standards confirm that it is a shared digital representation of physical and functional characteristics of any built object, which forms a reliable basis for decision-making process. Today, the suitability of BIM platforms for historical architecture is still considered a great challenge. The aim of this work is to think about and explore the capabilities of Historical Building Information Modeling (H-BIM) for historical building restoration, to combine the geometric accuracy of the survey with the parametric flexibility and wealth of information of BIM processes.

Going more into details, the authors focused on the chance to model 3D decays in the BIM platform, enriching the related database with graphic, geometric and alphanumeric data that can be used to design and manage future interventions.

The paper is organized as follow: section 2 will be dedicated both to the analysis of the state-of-the-art of integrated metric survey techniques used for $3 \mathrm{D}$ modeling reconstruction, and to the description of today's method of understanding and conceiving the restoration project. Section 3 briefly describes the case study, while the following sections describe the metric survey workflow and the subsequent BIM modeling phase.

The capabilities to link the virtual model to the restoration data are discussed in Section 6 and 7, while concluding remarks and new scenario offered by our approach and future development are outlined in Section 8.

\section{CURRENT DEVELOPMENT}

Regarding BIM methodology applied to Cultural Heritage, very little research has been undertaken to understand the potential of BIM for heritage buildings (Volk, 2014a, Biagini, 2016a). The challenge is still open if considering the conservation, management and enhancement of the architectural heritage. It is necessary to review and update the instrumental capture process of information, the standardization and structuring of acquired data in a $3 \mathrm{D}$ semantic model and the subsequent representation and usability of the obtained model.

The scientific community is trying to evaluate if the metric accuracy captured by laser scanner and photogrammetric point clouds can be preserved in the BIM platform, or rather is the level 
of abstraction too high for an appropriate geometry reconstruction. Some authors carry out a comparison - point cloud to model - (using Geomagic or Cloud Compare software) in order to evaluate if the deviation is in keeping with the scope of the Historical BIM. Others prefer to perform the 3D modeling in other platforms (also by using procedural modeling based on shape grammar) able to create and manage NURBS surfaces (that better approximate the trend and irregularity of complex surfaces) then they use proper protocols to directly convert NURBS into parametric surfaces into commercial BIM platforms (Murphy, 2013a).

It must be noticed that the high metric contents coming from digital Photogrammetry and LiDAR technologies is not always necessary to described a 3D model by considering the goals of the investigation. The modern approach of automatic acquisition of primary data at the highest possible resolution and accuracy push the intelligence of the metric survey in a second step where the surveyors have to select the needed information by considering the required accuracies and level of details. Those two aspects could change inside the same 3D model due to the different needs of the final users. Regarding to the semantic classification of each single building component, a further important consideration must be pointed out: 3D models that contain only 3D (metric) data are not BIM models.

\section{FROM THE KNOWLEDGE TO THE INTERVENTION: REPRESENTATION METHODS}

The development of a restoration project aimed at built heritage safeguarding requires the identification of a method that should opt for a scientific process applied time to time to each building. The implementation of this method allows reaching an adequate knowledge of the asset on which the intervention will be done and to reveal the results of investigation's activities making explicit and easily acquirable both geometric, constructive, structural characteristics and the designed intervention.

Knowledge should be assumed as a "synthesis" of an analytical process, whose results are shown through the project drawings. It recognizes and materializes itself in the metric survey, but must be supported with a deep analysis of materials, structures, constructive and architectural values of the building to be preserved. In particular, the design of a restoration intervention, aimed to the safeguard and, in accordance with the Italian Cultural Heritage Code, to the building enhancement, asks for the sharing of knowledge concerning structures, construction techniques and materials through a graphic and synchronic representation giving details about both defects and possible interventions.

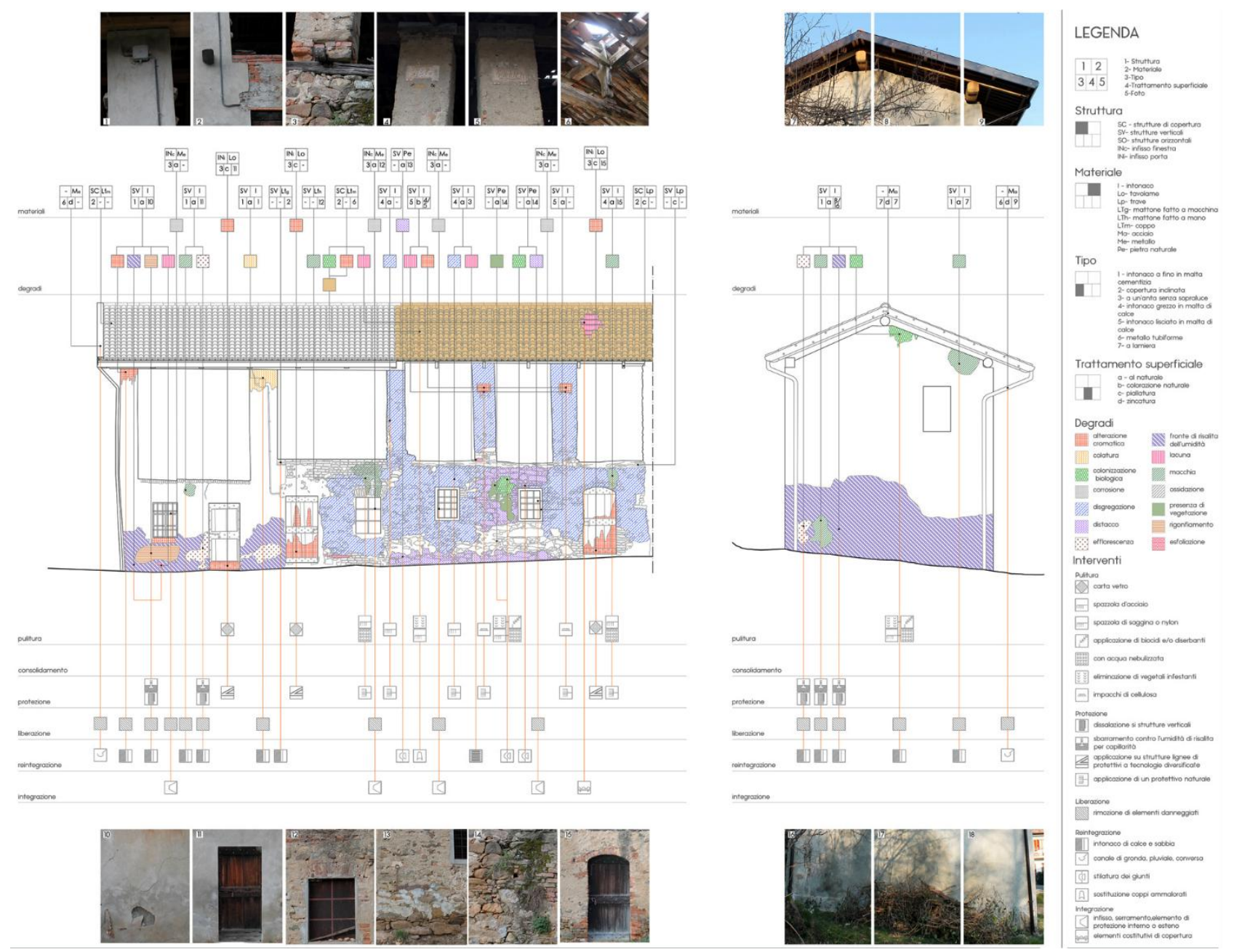

Figure 1. Example of a restoration project: from the analysis of materials and decays to the interventions' proposal 
At the end of the sixties of the twentieth Century, conservation science was born in Italy. Conservation requires to know and to intervene on an artistic artifact explaining all the information related to materials, mechanisms and causes of degradation, as well as to products and methodologies to be used during the restoration intervention. Therefore, the standardization of both analytical and intervention methods turned out to be a crucial point in the achieving of reliable results. For this purpose, in 1977 the Normal Commission was established in Italy. Its aim was to identify a unified methodology of analysis in the field of stone material conservation. The task assigned to the committee was in fact to establish standard methods for the study of stone materials alterations, and for monitoring the effectiveness of conservative treatment carried out on historical and artistic assets (Alessandrini, 1977). The committee dealt exclusively with stone materials referring with this term not only to natural stones, but also to artificial materials used in architecture, such as stuccos, mortars, ceramic products obtained starting from natural materials through special processes.

Almost simultaneously, studies and researches were set out to develop proposals aimed at rationalizing the entire design process for building preservation. In particular, Mario Dalla Costa (Dalla Costa, Ruol, 1986) proposed a new strategy concerning the way all the needed and useful information could have been shown by means of a graphic representation of both the state of conservation of the building and the designed interventions. Starting from the analysis elaborated by Normal Commission and by the methodological guidelines developed by Paolo Fancelli (Fancelli, 1983, Fancelli, 1984), a proposal, involving the use of icons to facilitate the comprehension of the building and the proposed intervention, was studied. Symbols, which could be modified and implemented from time to time depending on the needs, were drawn. All the information concerning building materiality, techniques and construction elements were given through those symbols.

This method is characterized by a refined flexibility, related to the change of materials, construction techniques, defects (degradations and/or structural problems) and strategies of intervention that one can come across.

This method has been the protagonist of a continuous improvement of the way of representation and data explanation since it has gone progressively adapting and enriching itself proving capability into grasping the opportunities offered by the evolution of the new technologies. From the initial manual representation, the method has moved to the use of computer tools and software that enable a more effective organization and systematization of the project's data and their eventual/possible quick revision following the acquisition of new information regarding the artifact to restore (Dalla Costa, 2000).

\section{THE CASE STUDY}

The analyzed case study belongs to Ferrovie dello Stato (the main Italian Railways Company) and it is part of the maintenance area, which was originally constituted by a roundhouse containing 51 sheltered railroad tracks and 2 big sheds. The buildings were erected at the beginning of the $\mathrm{XX}^{\text {th }}$ Century. In 1911, in fact, the Universal Exposition, aimed at celebrating the $50^{\text {th }}$ anniversary of the constitution of the Italian Kingdom, took place in Turin and many visitors were expected for the event (Bassignana, 2003). Therefore, to face the new requirements, due both to the increase of the number of locomotives and to their dimension changes, it was decided to build a new maintenance and storage area for the locomotives (Greppi, 1912).

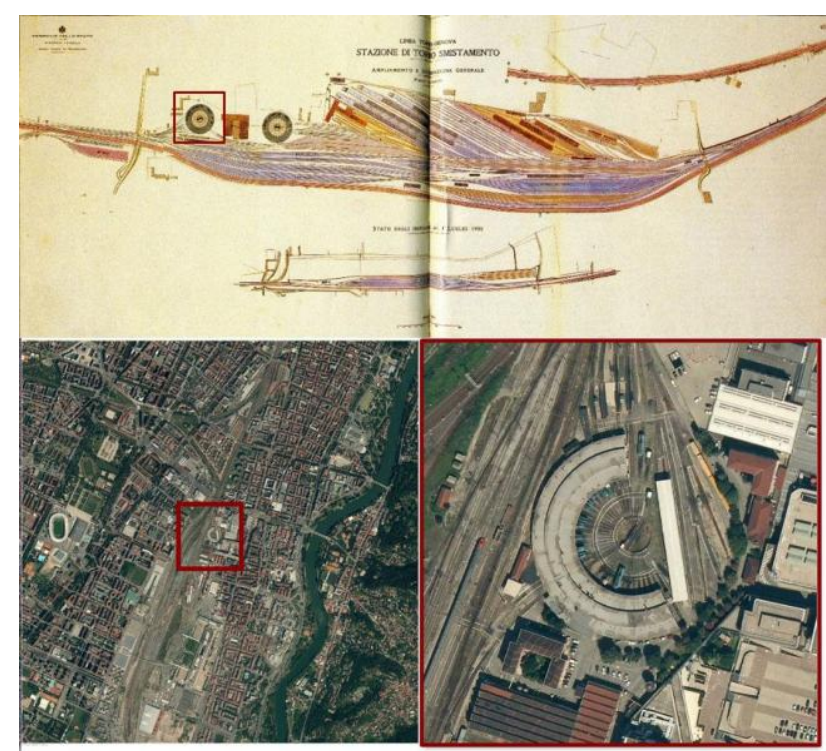

Figure 2. On the top, masterplan of the new intervention compared to the existing situation in 1905 (Ballatore, 1988). Below, recent orthophotos of the site

The roundhouse was the first one built in Italy and it constitutes an interesting example of industrial heritage. Partially destroyed during the Second World War, it is characterized by a structural repeated module which was built by Porcheddu Company adopting the Hennebique structural system. The module is constituted by three bays and it is sized to host a railroad-car. All rails are linked to a junction turning platform, in order to allow the allocation of the wagons inside each module. Nowadays, the building is seldom used and Ferrovie dello Stato would like to transform the roundhouse in a Railway Museum, therefore a restoration and an adaptive reuse intervention have been designed.

\section{THE METRIC SURVEY}

We are living during one of the most significant technological innovation period in both the metric survey and representation technologies. The most recent research perspectives in the field of Integrated Survey procedures are directed to the design a complex system that optimizes computing times, improves the efficiency and effectiveness of the entire process by making use of a wealth of interdisciplinary knowledge. The 3D model organizes the different levels of knowledge to be shared with other professionals involved for restoration plans.

The metric survey has been carefully planned by strongly considering the real needs and goals of the investigation aims to give the basic information for a complete restoration plan. It was decided to produce a 3D model of the building: this 3D model will be used to structure the other information by means of BIM technology.

A final accuracy of $5 \mathrm{~cm}$ was adopted due to the regularity of the shapes and to the facts that no structural problems were detected during the field inspection and the complete absence of decorated details. The building is subdivided in regular similar modular elements, therefore the metric survey was planned to define the relative location of the modules and a detailed survey of the interior and exterior surfaces of one single module. The module was selected by considering the real accessibility to all the needed parts of the structure: at present, the structure still recover old material and in some parts is not accessible.

To link all the detail survey interventions, a control network has been established in such a way to define a local coordinate system 
and to limit the error propagation. By considering the prefixed accuracy of $5 \mathrm{~cm}$, the precision of the detail points must be no more than $2.5 \mathrm{~cm}$ and therefore the control network has been planned with a precision of $5 \mathrm{~mm}$ in all the three dimensions $\mathrm{X}$, $\mathrm{Y}$ and $\mathrm{Z}$.

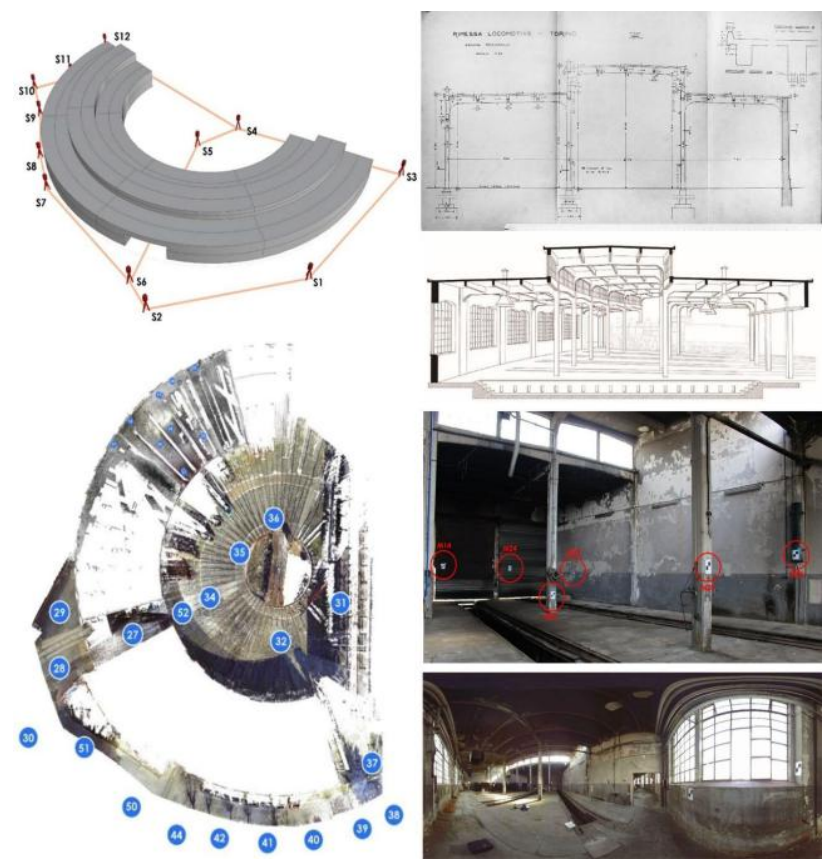

Figure 3. From the project survey up to the indirect acquisition and archival researches

The control network has been surveyed for the planimetry by using a total station and the survey scheme of the general network by measuring a sufficient number (almost two times the number of the unknown coordinates to be estimated) of angles and distances. The measurements were adjusted by using a rigorous approach (e.g. least square-based adjustment) by estimating the obtained precisions.

For the altimetry, the traditional differential levelling strategy was adopted by considering that the use of the total station on movable station points cannot guarantee the required precisions in the $\mathrm{Z}$ direction.

A second order control network has been established: it consists of the Ground Control Points (GCPs) useful to link together the different scans recorded inside and outside of the building. Beside the GCPs survey, a set of points that will not used for the survey have been measured. Those points are used as Check Points (CPs) to test the obtained accuracy after the modelling steps.

By considering the possibility to access the site, limited in time due to security problems, the Terrestrial Laser Scanning (TLS) technique was selected.

The goals and the subsequent defined strategies suggest making a low resolution scanning of the exterior part of the whole building and a set of indoor and outdoor high resolution scans for the module selected as base for the "copy and paste" reconstruction of the complete building.

The different scans have been registered in the coordinate system defined by the control network by using the GCPs previously described. A Phocus 3Dx330 laser scanner was used to acquire the point clouds and the images, and the SCENE software was used for the pre-treatment of the obtained data (registration and coloring of the points).

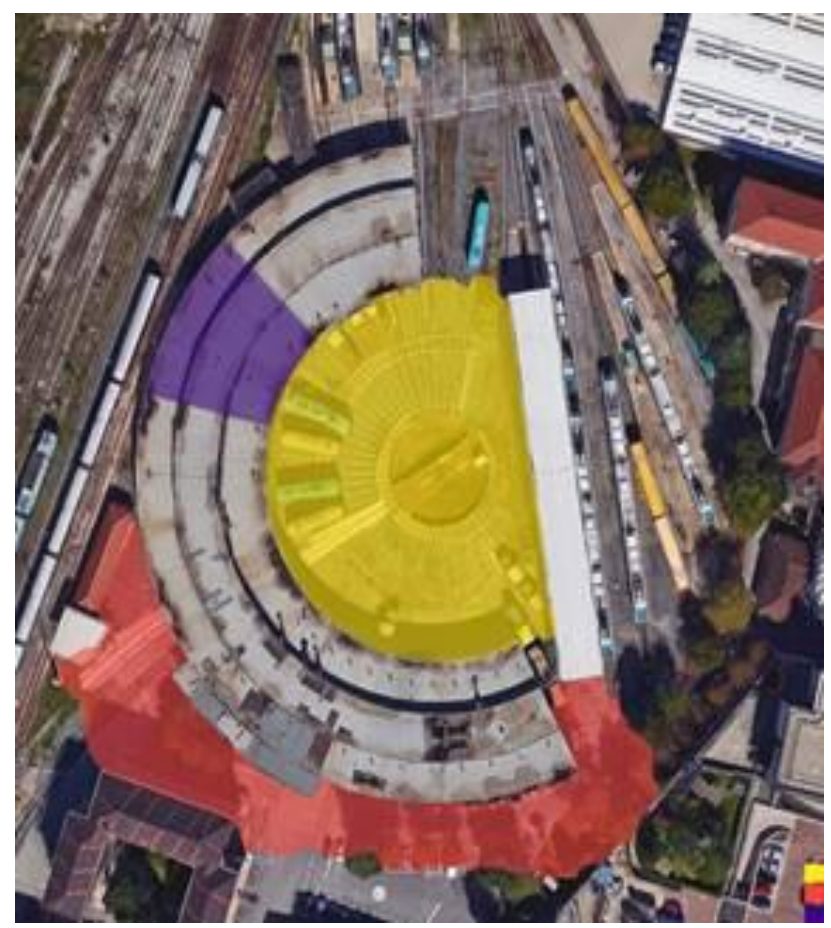

Figure 4. The thematic subdivision of the surveyed areas: in purple internal survey (TLS), in yellow external courtyard (TLS and SfM); in red topographic survey.

The final reached accuracy has been tested by using the CPs previously described and the maximum checked discrepancies never overcome the prefixed accuracy of the survey.

By considering the statistical result of the registrations, performed by using the software SCENE, the average residuals on GCPs was of about $4 \mathrm{~mm}$ with a standard deviation of about $\pm 2 \mathrm{~mm}$.

After the 3D modelling phase, a test on the surveyed CPs was performed: in this case, the average discrepancies are of about 9 $\mathrm{mm}$ with a standard deviation of $\pm 4 \mathrm{~mm}$, which allow accepting the result of the metric survey as correct in the accuracy fixed at the beginning.

The final part of the metric survey (the 3D geometric model construction) has been developed during the BIM implementation to speed up the procedure.

The main topics that were discussed during the modelling phase was the acceptance of some simplification of the geometric shapes coming out from the metric survey.

One of the discussed cases was the verticality of the walls: from the point clouds, some of the walls show non-verticality assets of about $10 \mathrm{~cm}$. Because the assessed accuracy of $5 \mathrm{~cm}$ those $10 \mathrm{~cm}$ surely suggest that the walls are not vertical. The discussion between the surveyors and the restorers put in evidence that the presence of those "normal" discrepancies are not caused by the stability of the building and can be generated by different effects (field-work mistakes and/or adaptation) which are not of interest in the planned restoration. Therefore, it was decided to hide this problem and allow the BIM modeler to assume those walls as vertical elements.

It is important to point out that each kind of simplification of a metric survey cannot be assumed due to the limits of the used modeling software but must be accepted only if this action will not affect the real aim of the survey. For these reasons, the modeling phase needs a collaborative effort to save the metric data contents and real goals of the survey. 


\section{3D SEMANTIC MODELING}

Since the architectural heritage has taken advantages from the development of data capturing technologies, an open issue is the integration of BIM systems and data source for existing buildings, supporting the creation of 3D knowledge and management systems. This work fits into an international research field about 3D modeling to evaluate the BIM performance for infographic representation of Cultural Heritage. Modeling an historic building involves the creation of parametric objects library starting from data survey. The primary purpose of the research is the translation of these information into a parametric model, through the definition of a proper methodology. The focus of the research is the creation of a parametric object representing the preservation status of materials and building components: some recurring schemes of the traditional representation have been identified, in order to find a methodology that leads to link these data to the HBIM model, improving their capabilities.

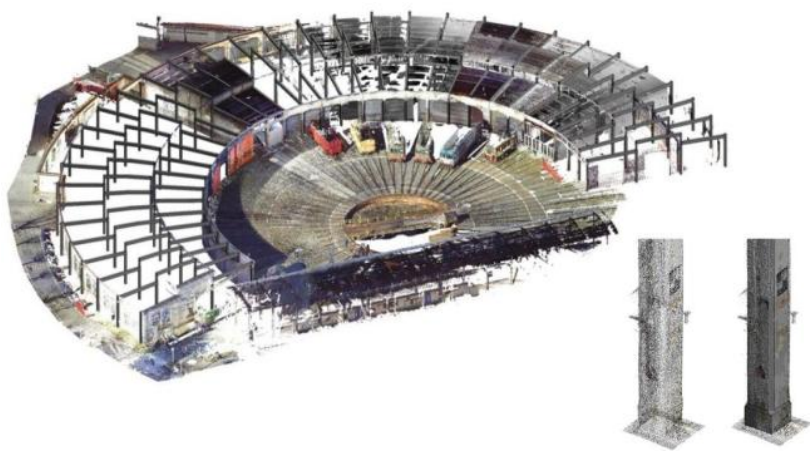

Figure 5. Comparison between the point cloud and the structural system of beams and pillars; on the right a cropped portion of the point cloud and the overlapping of the BIM model of a structural pillar

In order to achieve a better validation of the digital model, new parameters were added: some for the GRADE (GRAphic DEtail that define the detail level of the graphic representation) and LoD controls (Level of Development, meant as the degree of reliability of information associated with different elements). These are usually used in the design phase, when the information assets increase together with the design development; some new variables were added to assess the reliability degree and completeness of information element detected.

The modeling strategies in terms of parametric geometric models created for each building element have been verified by comparing the proposed models with the original point clouds, in order to accept the simplifications in an objective perspective. This approach allows simplifying the resulting 3D model by quantifying the loss of original metric data information.

\section{DATA COLLECTION FOR RESTORATION PROCESSES}

Regarding to the usual representation method proposed in the literature, all the information on dating and the consistency of the building are actually shown on the usual 2D drawings in orthogonal projections, applying a pattern element connected to a legend containing added data. Within the BIM model, geometries are represented through well-defined mathematical rules, thanks to the design of specific adaptive component able to be associated with flat and curved surfaces. The benefit consists in the ability to associate new parameters that describe both the state of conservation of the materials and the interventions needed to restore the building. Furthermore, information about materials, quantities (such as the decay extension, expressed in square meters) and photos can be added.

Therefore, multiple analysis can be done, making them more evident through multicriteria schedules defined by qualitative and quantitative data, preserving the production of traditional graphic drawing.
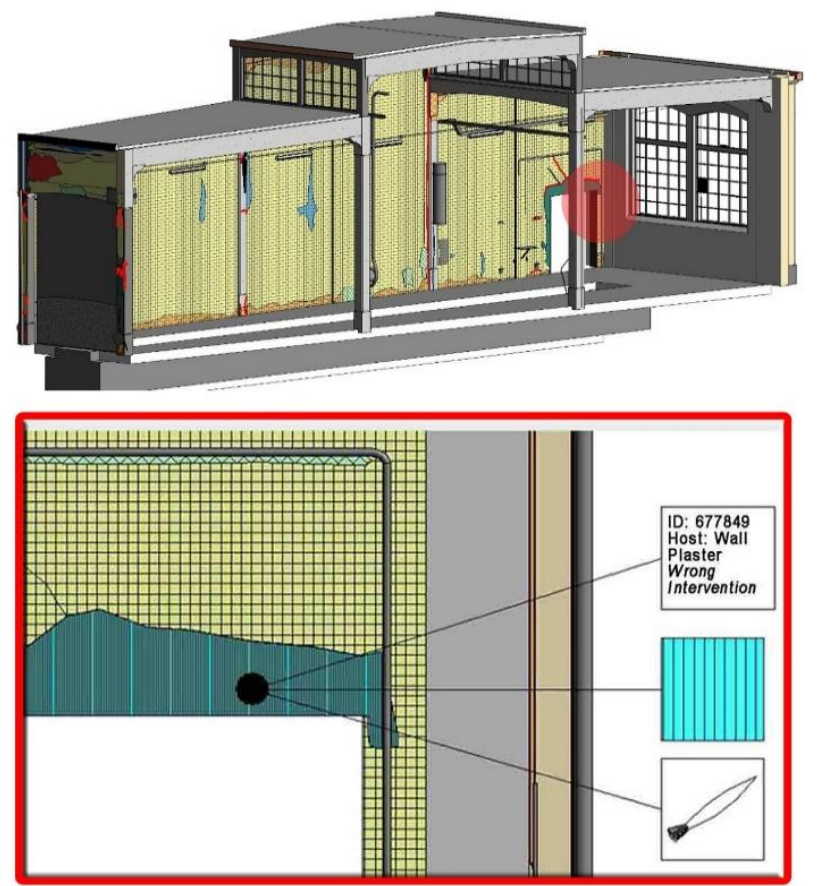

STONE MATERIAL'S DECAYS

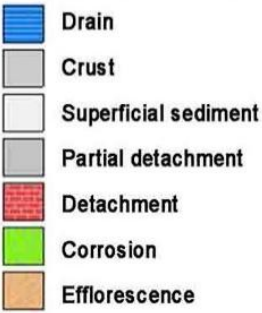

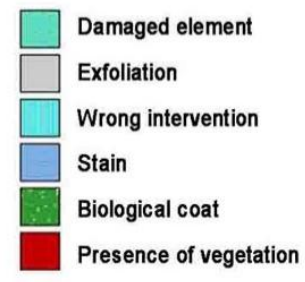

\section{CLEANING PROCEDURES}

\begin{tabular}{|c|c|}
\hline & $\begin{array}{l}\text { Biocides/herbicides } \\
\text { application }\end{array}$ \\
\hline & With nuke water \\
\hline & $\begin{array}{l}\text { Elimination of stains with } \\
\text { steel brush }\end{array}$ \\
\hline
\end{tabular}

\begin{tabular}{|c|c|}
\hline 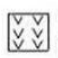 & $\begin{array}{l}\text { Elimination of infest } \\
\text { plants }\end{array}$ \\
\hline & $\begin{array}{l}\text { Manual removal with } \\
\text { spatula }\end{array}$ \\
\hline & $\begin{array}{l}\text { Manual removal of } \\
\text { detached plaster parts }\end{array}$ \\
\hline
\end{tabular}

Figure 6. 3D Modeling of decays and the graphic explanation of the data (through labels) associated to the adaptive component, such as the nature of the decay and the interventions required for cleaning

\section{CONCLUSION AND FUTURE DEVELOPMENT}

Concluding, the work tries to demonstrate that it is possible to develop and manage a HBIM model, starting from the checking of the metric accuracy: in particular, the transfer from numerical model (cloud of points) to a mathematical model (3D modeling) is a process that involves simplifications and deductive hypothesis (Santagati, 2016a). 


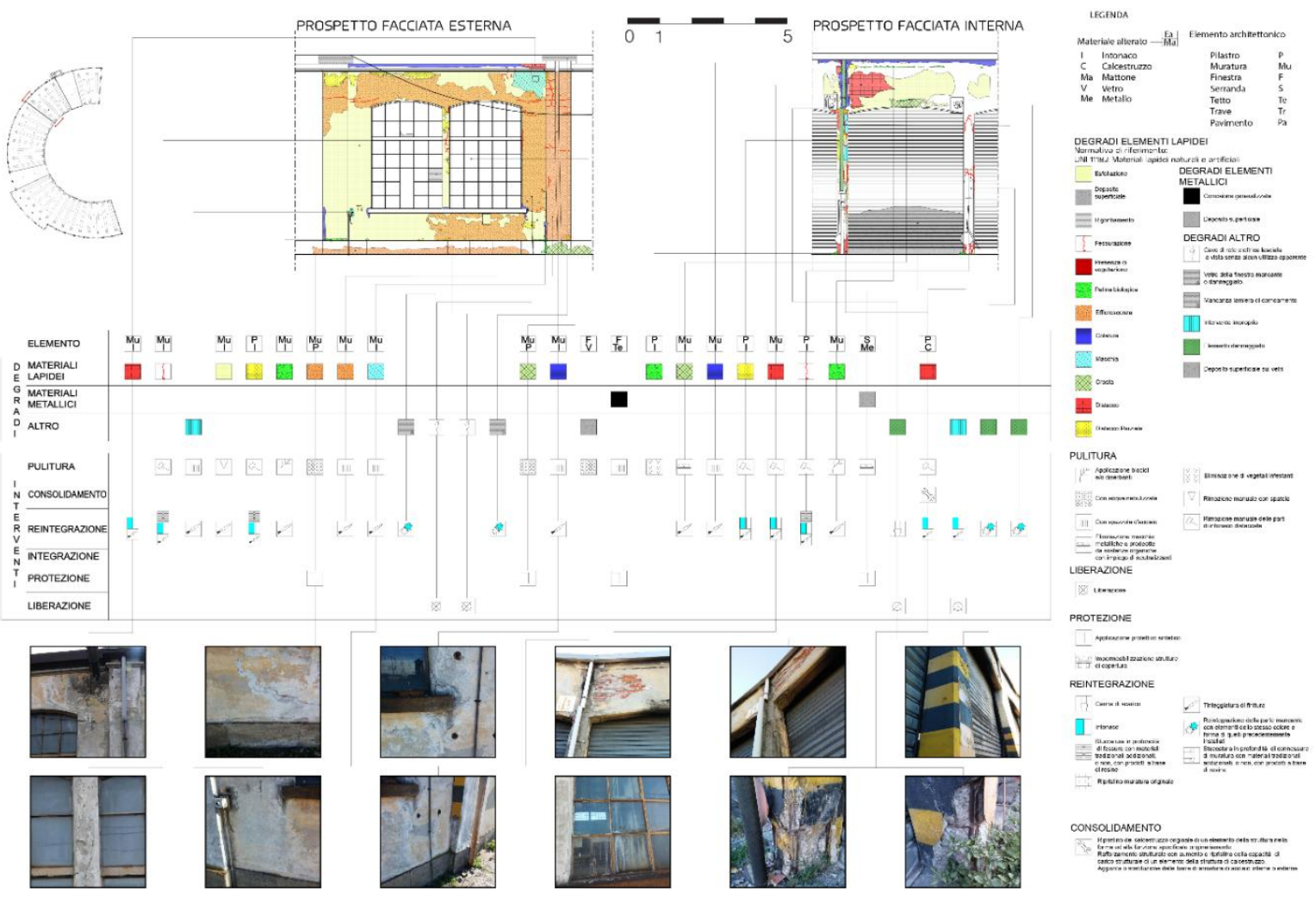

Figure 7. Thematic sheet composed by graphic and analytic description of the decay, enriched by pictures, encoding system, legend and description of the cleaning procedures. All these data are managed into the BIM environment

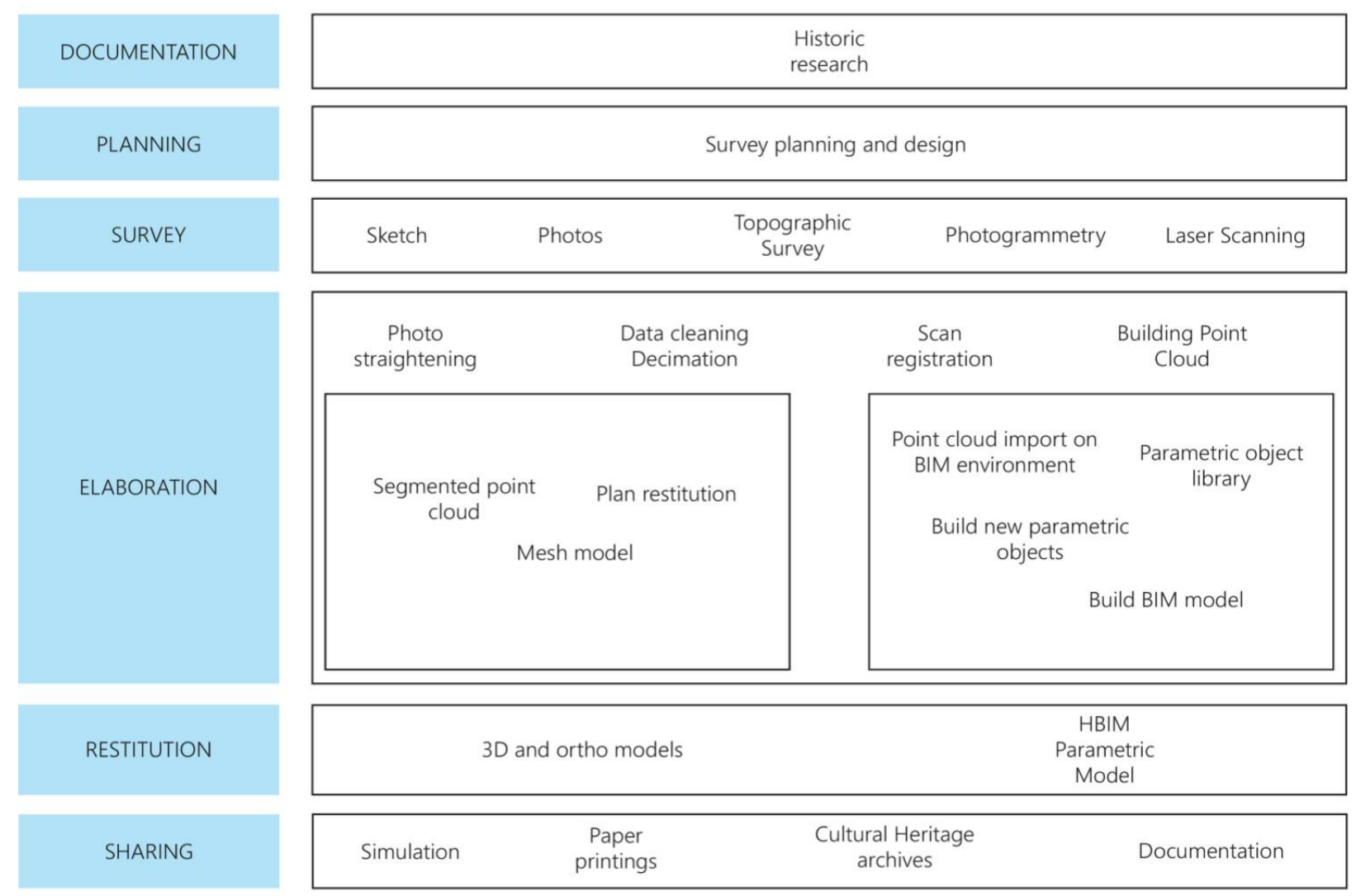

Figure 8. Graphic representation of the workflow 
On this issue, we would comment one topic more, related to different meaning of the word "measurability": the geometric issue is undoubtedly resolved and repeatedly mentioned in different documents that fully define the different metric detection operations. On the contrary, the ontological meaning intended as a quantitative enhancement of the reliability degree of a survey is not fully solved.

However, the proposed solution implies that the representation of the decays is managed by $3 \mathrm{D}$ elements, created through adaptive components. As the term suggests, these elements are able to approximate the true extent of degradation, especially those ones associated with curved surfaces such as the vaults. The graphical representation that derive will be consequently expressed in true form: this is very useful for quantifying the real extensions and annexes costs associated with restoration activities.

We agree in declaring that knowledge is the first stage of conservation and the conducted research corroborates this assumption. The opportunity to set up database in situ, even by less experienced users, significantly reduces the costs (of survey, drawing, design, construction and maintenance) because the data is not duplicated on the various applications and the information is no redundant, since it is a simple query of a shared virtual space. So, this guarantees a repeatability of the scientific process where the variable element is the data, the fixed one is the process (Inzerillo, 2013a).

These capabilities support interoperability scenarios, where the information, in various forms, can be made available to several professionals involved. Through interoperability traits, it is possible to figure out operating scenarios in which all actors can directly implement the recordings made in situ in an agile and accessible form. To do this, we need to support the object oriented paradigm with conceptual aspects of their relational approach to the management of heterogeneous data, numerous and constantly updated. The most recent lines of research are opting for database integration and web oriented tools, in order to be connected to the model. Furthermore, the entire documentation produced in different stages of intervention is stored and make accessible.

From a more scientific point of view, the application of these principles will allow to address and define a methodology for the knowledge (and the representation) of the Cultural Heritage, implying that the virtual reconstruction, the processing and communication of data become more transparent. It is therefore proposed a reflection on the infographic drawing, leading to a new form of design, and expanding the frontiers of our discipline. The concept of cultural dimension is thus a greater formal qualification in a permanent relationship between architectural space and information space.

\section{REFERENCES}

Alessandrini, G. et al., 1977. Artistic stone works. A proposal for the Unification of the Methods of Studying Stone Decay and of Controlling Stone Conservation. In: International Symposium on Conservation on Stone Materials, Bologna, Italy.

Ballatore, L., Masi, F., 1988. Torino, Porta Nuova: storia delle ferrovie piemontesi. Abete, Roma.

Barazzetti, L., Fangi, G., Remondino, F., Scaioni, M., 2010. Automation in Multi-Image Spherical Photogrammetry for $3 D$ Architectural Reconstructions. Vast 20102312.

Barrile, V., Bilotta, G., Lamari, D., \& Meduri, G. M., 2015a. Comparison between techniques for generating 3D models of cultural heritage. Recent Advances in Mechanics, Mechatronics and Civil, Chemical and Industrial Engineering, Mathematics and Computers in Science and Engineering Series, 49, pp. 140145 .

Bayram, B., Nemli, G., Özkan, T., Oflaz, O. E., Kankotan, B., \& Çetin, İ., 2015a. Comparison Of Laser Scanning And Photogrammetry And Their Use For Digital Recording Of Cultural Monument Case Study: Byzantine Land WallsIstanbul. ISPRS Annals of the Photogrammetry, Remote Sensing and Spatial Information Sciences, 2(5), 17.

Bassignana, L., 2003. Torino sotto le bombe. Nei rapporti inediti dell'aviazione alleata. Edizioni del Capricorno, Torino.

Biagini, C., Capone, P., Donato, V., Facchini N., $2016 a$. Towards the BIM implementation for historical building restoration sites. Automation in Construction , 71, pp. 74-86.

Bryan, P., Blake, B., \& Bedford, J., 2013. Metric survey specifications for cultural heritage. English Heritage.

Chiabrando, F., Spanò, A., 2013a. Points Clouds generation using TLS and Dense-Matching techniques. A test on approachable accuracies of different tools. ISPRS Annals of the Photogrammetry, Remote Sensing and Spatial Information Sciences, II, pp. 2-6.

Dalla Costa, M., Ruol, M., 1986. La conservazione della "fabbrica": problemi di rappresentazione dell'iter progettuale. In Biscontin, G. (ed.), Manutenzione e conservazione del costruito fra tradizione e innovazione, Libreria Progetto editore Padova, pp. 345-355.

Dalla Costa, M, 2000. Il progetto di restauro per la conservazione del costruito, Celid, Torino,

De Reu, J., Plets, G., Verhoeven, G., De Smedt, P., Bats, M., Cherretté, B.,\& Van Meirvenne, M., 2013. Towards a threedimensional cost-effective registration of the archaeological heritage. Journal of Archaeological Science, 40(2), pp. 1108 1121.

Fancelli, P., 1983. Il progetto di conservazione. Guidotti. Roma.

Fancelli, P., 1984. Forme di degrado e metodi per contrastarle: verso una normalizzazione grafica. In Storia e restauro dell'architettura: aggiornamenti e prospettive, Front Cover, Roma, pp. 765-802.

Fassi, F., Fregonese, L., Ackermann, S., \& De Troia, V., 2013a. Comparison between laser scanning and automated 3D modelling techniques to reconstruct complex and extensive cultural heritage areas. International Archives of the Photogrammetry, Remote Sensing and Spatial Information Sciences, 5, W1.

Greppi, L. Rolla, F., 1912, I nuovi depositi-locomotive delle Ferrovie dello Stato. Descrizione generale del deposito di Torino (smistamento). Rivista tecnica delle ferrovie italiane, 2, pp. 81-89.

Hess, M., Petrovic, V., Meyer, D., Rissolo, D., \& Kuester, F., 2015. Fusion of multimodal three-dimensional data for comprehensive digital documentation of cultural heritage sites. In Digital Heritage, (Vol. 2), pp. 595-602.

Hichri, N., Stefani, C., De Luca, L., Veron, P., Hamonet, G., 2013 a. From Point Cloud To BIM: a Survey of Existing Approaches. International Archives of the Photogrammetry, Remote Sensing and Spatial Information Sciences, XL-5/W2, pp. 343-348. 
Inzerillo L., Santagati C., 2013a. Using dense stereo matching techniques in survey. Disegnare Idee Immagini, 47/2013, Gangemi, Roma, pp. 82-91.

Lo Buglio, D., De Luca, L., 2012a. Representation of architectural artifacts: definition of an approach combining the complexity of the $3 \mathrm{~d}$ digital instance with the intelligibility of the theoretical model. SCIRES-IT SCIentific RESearch and Information Technology, Vol 2, Issue 2, pp. 63-76.

Lo Turco M., Sanna M., 2010a. La modellazione digitale ricostruttiva: il caso della chiesa della Misericordia a Torino. Disegnare Idee Immagini, Volume 21, Issue 41, December 2010, pp. $42-51$.

McCarthy, J., 2014a. Multi-image photogrammetry as a practical tool for cultural heritage survey and community engagement. Journal of Archaeological Science, 43, pp. 175185.

Moussa, W., 2014. Integration of digital photogrammetry and terrestrial laser scanning for cultural heritage data recording (Doctoral dissertation, University of Stuttgart).

Murphy, M., McGovern, E., Pavia, S., 2013a. Historic Building Information Modelling - Adding intelligence to laser and image based surveys of European classical architecture. ISPRS $J$ Photogramm Remote Sens, 76, pp. 89-102.
Politecnico di Torino. Archivio Porcheddu. Cart. 3316, 1909. Rimessa Locomotive, Calcoli - Disegni - Liquidazione Corrispondenza.

Quattrini, R., Malinverni, E. S., Clini, P., Nespeca, R., Orlietti, E., 2015a. From TLS to HBIM: high quality semantically-aware 3D modeling of complex architecture. International Archives of the Photogrammetry, Remote Sensing and Spatial Information Sciences, 40(5/W4), pp. 367-374.

Santagati, C., Lo Turco, M., 2016a. From structure from motion to historical building information modeling: populating a semantic-aware library of architectural elements. J. Electron. Imaging, 26(1), 011007.

Volk, R., Stengel, J., Schultmann, F. 2014a. Building Information Modeling (BIM) for existing buildings - Literature review and future needs. Autom Constr, 38, pp. 109-127.

Yastikli, N., 2007a. Documentation of cultural heritage using digital photogrammetry and laser scanning. Journal of Cultural Heritage, 8(4), pp. 423-427.

Yilmaz, H. M., Yakar, M., Gulec, S. A., \& Dulgerler, O. N., 2007a. Importance of digital close-range photogrammetry in documentation of cultural heritage. Journal of Cultural Heritage, 8(4), pp. 428-433. 